\title{
2. MEDIOS DE COMUNICACIÓN Y DEMOCRACIA
}

\section{DIEZ RASGOS DE LA NUEVA OPINIÓN PÚBLICA}

\section{Víctor Sampedro Blanco*}

Fecha de recepción: febrero 2000

Fecha de aceptación y versión final: abril 2000

Resumen: Se realiza una revisión de las transformaciones de los espacios en los que se crea y expresa la opinión pública con la aparición de los medios masivos y los sondeos. Agrupadas en diez rasgos, estas transformaciones sirven para introducir los trabajos de los autores que colaboraron en este monográfico.

Palabras clave: Medios de comunicación, opinión pública, sondeos de opinión, modernidad, efectos mediáticos, democracia deliberativa.

Abstract: The author presents a theoretical overview of the transformation of the public spheres due to the consolidation of mass media and opinion polls. Ten traits of the new public opinion offer a framework to introduce the articles included in this monographic issue.

Key words: Mass media, public opinion, opinion polls, modernity, media effects, deliberative democracy.

Con el término opinión pública nos referimos a las opiniones de la gente común que son tenidas en cuenta por los que ejercen el poder (Key, 1967). La definición deja fuera todo lo que el pueblo piensa y delibera sin afectar la gestión política, porque no se plantea en términos de voluntad colectiva. Los medios de comunicación y los sondeos se han erigido en representantes cotidianos y hegemónicos de las opiniones ciudadanas, remplazando a las instituciones tradicionales de representación. Presentaré diez rasgos de la nueva opinión pública que nos permiten encuadrar teóricamente los restantes trabajos que ofrecemos sobre comunicación política en este monográfico de América Latina Hoy.

Resulta innegable que medios y sondeos ha alterado las relaciones entre poder democrático y voluntad popular. Así lo señalan las contribuciones de Raúl Trejo, Jacqueline Peschard y Mauro Pereira. Trejo se mantiene en un nivel teórico, Peschard presenta a los medios como elementos normalizadores de los últimos procesos electorales mexicanos y Pereira vincula la actuación mediática y la legitimidad democrática en Brasil. Pero veamos un momento la evolución de las técnicas de expresión de la opinión pública, tal como las presenta Susan Herbst (1993: 61).

\section{Técnicas de expresión de la opinión pública}

$\begin{array}{llll}\text { Cronología } & \text { Técnicas de la opinión públicas } & \text { Estructurada } & \text { Pública / Privada } \\ \text { c. V a.C } & \text { Oratoria y retórica } & \text { no } & \text { pública } \\ \text { s. XVI } & \text { Imprenta } & \text { sí } & \text { pública y privada } \\ \text { s. XVII } & \text { Muttitudes } & \text { no } & \text { pública y privada } \\ \text { fin. s. XVII } & \text { Peticiones } & \text { sí y no } & \text { pública } \\ \text { fin. s. XVII } & \text { Salones } & \text { no } & \text { pública } \\ \text { fin. s. XVIII } & \text { Movimientos. revolucionarios } & \text { no } & \text { pública } \\ \text { s. XIX } & \text { Huelgas } & \text { no } & \text { pública } \\ \text { s. XIX } & \text { Elecciones generales } & \text { sí } & \text { privada } \\ \text { mitad s. XIX } & \text { Prensa moderna } & \text { sí } & \text { privadal } \\ \text { mitad s. XIX } & \text { Cartas al director y personajes públicos } & \text { sí } & \text { privadda } \\ \text { s. XX años } 20 \text { y } 30 & \text { Medios de comunicación } & \text { sí } & \text { pública y privada } \\ \text { s. XX años } 30 & \text { Sondeos } & \text { sí } & \text { privadal }\end{array}$

Desde la Grecia clásica hasta nuestros días, la opinión pública se somete al proceso de racionalización burocrática que conceptualizó Max Weber. La voluntad popular se gestiona progresivamente en burocracias que permitieron la transición de las pequeñas comunidades a la coordinación social a gran escala de los Estados nacionales (Weber, 1984: 741). Con retraso cronológico la evolución se constata también en América Latina con dos notas características: la estructuración y la privatización de la opinión pública.

Profesor Titular de Opinión Pública. Universidad de Salamanca. Dpto. de Sociología y Comunicación. $\square$ sampedro@gugu.usal.es 
Se priman expresiones cada vez más estructuradas, porque para pulsar, representar y difundir la opinión pública es preciso contar con mayores recursos. Sin duda, los mejor emplazados en las estructuras sociales siempre tuvieron más ventajas para participar en el debate colectivo. De los 60.000 ciudadanos de la Atenas del s. V a.C., sólo unos miles cabían en el ágora y apenas unos cientos de nobles participaban en los debates. Pero la posibilidad teórica de acudir y ser escuchado permanecía abierta. Por otra parte, la opinión pública ha pasado a expresarse y percibirse en el ámbito privado. La plaza y la calle han sido sustituidas por urnas, sondeos y medios domésticos que adquieren una forma cada vez más privada; por ejemplo, la radio walk-man, los televisores y los ordenadores personales.

En suma, las técnicas de expresión más recientes, los sondeos y los medios audiovisuales, constituyen una "nueva institución social" (Beniger y Herbst, 1990) que altera o relega las formas de representación política tradicional, como el parlamento y los partidos. Sin embargo, tal como señala Silvio Waisbord en su artículo de este monográfico, la homogeneización de las esferas públicas nacionales, resultado de los flujos globales de capital y tecnología, se acomoda a la práctica y a las instituciones políticas, generando también importantes diferencias nacionales.

Como se ha apuntado, la implantación de los nuevos gestores de la opinión pública se inició en Occidente a mediados del XIX, cuando ésta perdió carácter local, debiendo legitimar a los líderes de los estados nacionales. En ese momento, las expresiones basadas en una relación personal con la autoridad (p.e. las peticiones del pueblo al monarca) se hacen más abstractas. La opinión pública adquiere un ámbito relativamente autónomo, haciéndose oír en asambleas, manifestaciones, huelgas, marchas reivindicativas, invasiones de cámaras de representantes, insurrecciones y movimientos de masas. Pero en el s.XX, después de la década de los treinta, la estadística permite analizar la opinión de grandes poblaciones a partir de muestras representativas. La televisión nacional y la demoscopia convergen en un "nuevo paradigma" marcado por los estudios de audiencia (Beniger, 1987). Junto con el sufragio universal, la televisión y los sondeos constituyen un entramado de instituciones que, no sólo refleja, también condiciona las preferencias ciudadanas al monopolizar su expresión y difusión.

Como advirtió Max Weber, el balance es ambiguo. Las burocracias de la voluntad popular no son democratizadoras en sí mismas. Igualan a los ciudadanos al considerarlos votantes, miembros del público y encuestados con idéntico valor. Pero no fomentan su participación. Los ciudadanos sólo intervienen suscribiendo las alternativas que se les proponen: un líder, un programa o las respuestas de un sondeo. Cuentan, se les cuenta como meros números (Weber, 1984: 739). Detallaremos diez rasgos de la nueva opinión pública: estructurada, impersonal, formalizada, ubicua, celérica, reflexiva, tautológica, intercambiable, racionalizada y populista. Sensibles a su ambivalencia, intentaremos señalar la vertiente positiva y negativa de estos adjetivos 1 .

(1) La representación de la opinión pública contemporánea está estructurada por los elevados costes que requiere.
La capacidad de financiar campañas electorales, medios y sondeos se concentra en pocas manos. Por otra parte, la recepción de los mensajes también se segmenta según las estructuras sociales. Por ejemplo, la información más precisa y relevante se ofrece en las televisiones privadas de pago, destinadas a los grupos más ricos de la audiencia. Tras el desmantelamiento de los medios públicos, las televisiones comerciales han reducido esos contenidos al mínimo. Las cadenas de "libre acceso" (financiadas por publicidad) se convierten con facilidad en guetos culturales, plagados de productos sensacionalistas, de bajo coste y dirigidos a los sectores más desfavorecidos y despolitizados. Esta esfera pública privatizada erige compartimentos casi estancos. Y, sin embargo, hay que reconocer que nunca como en la actualidad el ciudadano medio ha podido disponer de tal cantidad de informaciones. Existe segmentación, pero también sobreabundancia de mensajes, relevantes al menos para quienes puedan costearlos y tengan el tiempo y el conocimiento para seleccionarlos.

El artículo de Daniel Hallin, que incluimos en este número de América Latina Hoy, examina el rol ambivalente de la información sobre sucesos en la esfera pública de México. Con acierto señala los sesgos de la representación mediática del crimen, la fusión de géneros informativos y de entretenimiento, y las diferencias entre programas dirigidos a sectores sociales segmentados según su capacidad adquisitiva. La tendencia al sensacionalismo está ligada, según Hallin, a dos cambios estructurales de la sociedad mexicana: la democratización y la comercialización. El mismo objeto de estudio reaparece en la contribución de Ricardo Gutiérrez. En su análisis de los telenoticieros argentinos nos desvela las definiciones mediáticas del crimen, así como el papel atribuido a las instituciones políticas y a los propios medios en las noticias sobre ese "problema social". Las distintas metodologías que emplean estos dos autores aportan argumentos complementarios a la tesis de las dificultades de la ciudadanía para entender y participar en una solución política de los problemas del orden y la justicia en nuestras sociedades.

(2) La opinión pública actual se despersonaliza. Se garantiza el anonimato para suscribir o rechazar un opción política en las urnas, ante un encuestador o en frente de la televisión. Esto favorece la libertad individual, pero rebaja la implicación y la responsabilidad. Cabe cuestionarse si las opiniones personales son verdaderamente públicas, cuando a lo mejor los ciudadanos no confesarían abiertamente ante los demás su voto, qué respondió a una encuesta o el programa que vio. Pero los medios ya no interpelan a una comunidad de lectores conocida y próxima para movilizarla políticamente. Se dirigen a un consumidor de perfil abstracto, apenas definido por los rasgos sociodemográficos que interesan a los publicitarios; sobre todo, el nivel de ingresos.

1. Para una revisión de la literatura sobre opinión pública en la que me he apoyado, véanse Margolis y Mauser (1989); Glasser y Salmon (1995); Glynn y otros (1999); y Sampedro (2000b). 
Algo parecido ocurre con la demoscopia. El uso prioritario de las encuestas ya no reside en detectar problemas o condiciones sociales que demandan la intervención pública, tal como ocurría en sus primeras aplicaciones. La mayoría de los sondeos son estudios de mercado que pretenden identificar a los potenciales consumidores de programas electorales, bienes o servicios. En todo caso, los medios atienden o descubren nuevas demandas, pero con el fin de satisfacerlas al mínimo coste. De ahí, el mínimo común denominador que impera en las propuestas políticas y los programas destinados a las grandes masas.

(3) Representar la opinión pública exige un alto grado de formalización. Hacer política, información o encuestas es cuestión de expertos. Pero no participar en una manifestación o en una asamblea. En este punto resulta preciso recordar que un gobierno de técnicos puede asegurar eficiencia y eficacia en la toma de decisiones, pero no su representatividad. Con todo, el debate público actual se considera "tan especializado que se acepta que esté limitado a sus profesionales, a los que conducen la política y a los que informan sobre ella, a los que hacen encuestas y a los que las citan, a los que preguntan y a los que contestan las preguntas en los programas televisivos, a los consultores mediáticos, a los columnistas... al puñado de iniciados que inventan, un año sí un año no, la narrativa de la vida pública" (Didion, citado en Carey, 1995: 375).

Dentro de esta problemática, Rossana Reguillo nos aporta una interesante reflexión sobre los problemas de los movimientos indígenas para consolidar la imagen de ciudadanía en tiempos de globalización. Las estrategias para construir una identidad mediática, firme y diferenciada son tarea urgente de los grupos sociales (auto)excluidos. Debatiéndose entre el pasado y la modernidad, entre el centro y la periferia de sus sociedades, los movimientos populares de América Latina buscan en los medios un espacio de representación de difícil acceso y efectos contradictorios. El caso del EZLN mexicano le sirve a la autora para ejemplificar estos argumentos.

(4) La opinión pública ofrece ahora una imagen ubicua, presente para cualquier ciudadano en todas partes. Aunque nos resistamos e ignoremos las campañas electorales, ya no podemos acudir a las urnas desconociendo los pronósticos de las encuestas o los eslóganes partidistas. Nos habremos enterado en conversaciones circunstanciales, por la propaganda diseminada por doquier o por referencias cruzadas en cualquier noticia. La presencia y la constatación continua de la opinión pública mayoritaria puede inducir al silencio de las minorías (Noelle-Neumann, 1984). Pero también afecta a los dirigentes, expuestos al ojo público incluso en sus residencias oficiales y privadas. La planificación de cada aparición mediática resulta crucial para aguantar en la cresta de las encuestas. El control, por tanto, afecta tanto a gobernados como gobernantes, pero con escaso concurso de los primeros.

Ese discurso mediático dominante y ubicuo imprime efectos muy significativos en el sistema político. El estudio empírico de Orlando D'Adamo, Flavia Freidenberg y Virginia García Beaudoux, sobre el establecimiento de la agenda en Argentina, confirma la poderosa influencia cog- nitiva de los medios. Éstos dirigen la atención pública hacia determinados problemas sociales. Fijan, por tanto, los temas que están en la cabeza de los ciudadanos cuando piensan en términos colectivos y cuando se alinean respecto a las opciones políticas en liza.

(5) El ritmo de mudanza de las representaciones de la opinión pública resulta vertiginoso. Sólo lo estabiliza la aceptación de los resultados electorales hasta los próximos comicios. Gobernar por presión de las encuestas o de los titulares exige fijar objetivos a corto plazo, revisables por giros inesperados de la opinión publicada o sondeada. La búsqueda mediática de novedades conduce a una actividad política en apariencia frenética, pero que puede resultar irrelevante, pura imagen. Es también cierto que periodistas y sondeadores transmiten demandas nuevas y contradictorias a los gestores. Pero su pronta saturación con el mismo tema (hay que elaborar más noticias y encuestas), dificulta que afecten las agendas de gobierno y, menos aún, que fiscalicen su cumplimiento. De hecho, ocupar la esfera pública, de cualquier modo y por cualquier medio, parece ser la actividad política más importante hoy en día.

La propia dinámica de los medios tiende a favorecer la retórica del "ganador". Los periodistas organizan los enfrentamientos entre líderes y reparten los laureles de un triunfo simbólico que ellos mismos otorgan. En la medida en que este manejo de la información repercute en las urnas, aparecer y parecer como "triunfador" se ha convertido en el eje de las campañas electorales. Todas las contribuciones de este número especial de América Latina Hoy subrayan los cinco rasgos de la opinión pública contemporánea que hemos señalado y, en un nivel más abstracto, confirman las cinco notas restantes.

(6) Propias de la Modernidad tardía (o posmodernidad), las representaciones de la opinión pública son, como aquélla, reflexivas. Representan al público y a los gobernantes, con imágenes que se convierten en identidades con fuerza propia: establecen distinciones y condicionan los comportamientos de gobernantes y gobernados. Se construyen y se reproducen mayorías y minorías sociales según voten, consuman ciertos medios o respondan a las encues. tas. Por ejemplo, las cuotas de audiencia encuadran a los ciudadanos en públicos femeninos o masculinos, jóvenes o adultos, con opiniones y gustos definidos y homogéneos Sin embargo no parece que el público les confiera el significado que les atribuyen sus gestores. ¿Por qué considerar que los lectores de un periódico comulgan con los editoriales? ¿No sería como afirmar que quienes leen al Marqués de Sade practican el sadomasoquismo? Algo semejante ocurre con las encuestas, ¿por qué distinguen la opinión de las mujeres y de los hombres cuando coinciden o muestran diferencias no significativas? ¿No afirman así diferencias de género inexistentes en muchos temas?

Pero también (¿sobre todo?) los dirigentes se ven a sí mismos a través de las imágenes que de ellos proyectan los medios y las encuestas. Actúan en consecuencia y toman decisiones según los informes de prensa que elaboran sus equipos cada mañana. Lanzan filtraciones o globos sondas para adelantar las respuestas del electorado. O se fabrican la etiqueta de "grandes comunicadores" interactuando con 
un grupo muy reducido de publicistas. Ronald Reagan, por ejemplo, recibió ese epíteto de un círculo de elites que lo propagó sin fundamento. En sus dos primeros años de presidencia no recibió más apoyo en las encuestas que sus precedentes. Aunque esto no impidió que el público asumiese una falsa auto-imagen, Reagan fue desde el comienzo "uno de los presidentes más queridos por su pueblo" (King y Schudson, 1995). ¿De cuántos caudillos populistas latinoamericanos podría decirse lo mismo?

(7) La opinión pública resulta casi tautológica y circular: se define como "lo que sondean los sondeos" (Blumer, 1948). Y lo público es lo que publican los medios. Encuestas y noticias provienen de un entramado de instituciones interconectadas que comparten personal. Los sociólogos y politólogos más conocidos trabajan en la Universidad y dirigen institutos de sondeos que prestan servicios indistintamente a los partidos, la Administración, los medios y las empresas. Tampoco es extraño que hayan ocupado puestos de responsabilidad política, al igual que los hombres fuertes de los grupos de comunicación. Pero se ha de reconocer, al mismo tiempo, que los grupos que compiten en la esfera pública intentan dotarse de medios, encuestas y portavoces políticos que promueven sus demandas. Se libra así una batalla, a veces desigual a veces más equilibrada, por atraerse la opinión pública; a ser posible "fabricándola" mediante representaciones favorables.

(8) De hecho, las instituciones de la opinión pública presentan imágenes intercambiables de la voluntad popular. Según las circunstancias e intereses del momento, la opinión pública pasa a ser representada por editoriales, encuestas o urnas. Gobierno, oposición y ciudadanía apelan a esas tres instancias para legitimar posiciones contrarias, argumentando falsas equivalencias según su conveniencia. Más peligroso aún resulta que se hayan erigido en medidas de éxito o fracaso e, incluso, de calidad democrática. Se ha impuesto (¿quién, sino ellos mismos?) la idea de que la democracia triunfa día a día gracias a los medios y los sondeos. Y que este dúo ejerce una función democrática si influye o más aún si desplaza a los gobernantes.

Consideremos el curso de un proceso común de corrupción política. Suele comenzar con filtraciones a los medios, provenientes de actores desplazados de los puestos de poder o con ganas de coparlos. La información se presenta a la audiencia como fruto del "periodismo investigación", cuyo éxito se cifra en las comisiones parlamentarias "de investigación" o los procesos judiciales que provoca, y los posteriores ceses o dimisiones. La soberanía ciudadana en las urnas y el control recíproco entre los tres poderes clásicos se desdibujan en el plebiscito permanente de las cuotas de pantalla o las encuestas de popularidad. El protagonismo político corresponde al cuarto poder.

(9) Esas representaciones de la opinión pública parecen haberse convertido en fines en símismos. Los medios ya no tienen como función elevar la participación y la educación de los ciudadanos. Sólo han de darles "lo que quieren", reducido absurdamente a los índices de audiencia: el número de televisiones encendidas y sintonizadas en un canal. Así se puede defender la desregulación absoluta del mercado comunicativo, al margen de los efectos que provoque. Por supuesto que la libertad de asociación política, de expresión y de empresa informativa son derechos individuales. Pero se nos ha olvidado (¿quién nos lo recuerda?) que cuando se formularon se basaban en la premisa de que existía un público independiente. Éste era un colectivo con derecho a debatir y participar. Ese derecho colectivo a la información justifica los privilegios que disfrutan los representantes políticos (inmunidad parlamentaria) o comunicadores (secreto profesional), cuyas libertades individuales cobran así mayor sentido, un fin superior (Carey, 1995).

Toda forma de representación que se arrogue la exclusiva y el monopolio de la opinión pública resulta ilegítima en democracia. Más aún, si abandona su verdadera función: que la gente común y no los representantes determinen el interés colectivo. Políticos, periodistas y encuestadores parecen haber optado por la cooperación simbiótica, en defensa de los intereses particulares de sus organizaciones (exclusivas oficiales a medios afines, buena publicidad a cambio de favores en la regulación de medios, cartera de clientes comerciales y públicos de las empresas de sondeos). Sin controlarse mutuamente, a veces resulta obvio que los gestores de la opinión pública empobrecen el debate democrático y dificultan el acceso de los ciudadanos a una realidad política que aquéllos construyen sin apenas antagonistas.

(10) En un nivel aún más abstracto, las representaciones contemporáneas de la opinión pública transmiten una falsa racionalización de la actividad política, que se tiñe de un populismo no menos falso (Edelman, 1995). Convencer al público de que se le tiene en cuenta día a día, hora a hora e incluso en tiempo real, tranquiliza y, por tanto, desmoviliza. Se sostiene así que las demandas ciudadanas son medidas, canalizadas y sopesadas por expertos y líderes gracias a sus conocimientos y sacrificios. Los números de votos, audiencias y encuestas, como los de la economía, eliminan toda reflexión política y resultan inapelables en boca de sus contables.

Pero la frialdad de las cifras debe paliarse con el populismo de las grandes palabras. Se afirma que la política racional (la única posible) consiste en flexibilizar el mercado de trabajo y reducir la inversión estatal. Sin embargo, todo candidato promete pleno empleo y más servicios sociales en cada campaña electoral. La esquizofrenia se mantiene porque los periodistas reproducen ambos mensajes con igual intensidad. Y porque los encuestadores confirman el respaldo ciudadano tanto a los objetivos sociales como las políticas "razonables". En España, por ejemplo, recogen el paro como primera preocupación de los españoles y su "satisfacción" en los barómetros de perspectivas económicas. En consonancia con el lema de la fuerza ganadora en las elecciones del 2000: siempre vamos bien y a mejor (Sampedro y Jerez, 2000).

La racionalidad económica (sólo se costea lo que genera beneficios o no provoca costes) impregna las instituciones de la opinión pública. El discurso social está sometido, como sostiene Habermas (1986 y 1987), a la "racionalidad técnico-burocrática". Sólo deben realizarse políticas que redunden en votos, informaciones y encuestas que se vendan bien. Esto bien podría generar a corto plazo una ofer- 
ta informativa representativa de las preferencias ciudadanas, pero disminuye su capacidad de razonamiento. Porque de partida el discurso político mediatizado descarta beneficios y objetivos alternativos. Y oculta que la definición de costes y beneficios resulta siempre ideológica. ¿Quién los determina? ¿Los que pagan el precio o los que reciben beneficios? ¿Y qué marco temporal se tiene en cuenta?

Reparemos en el discurso mediático sobre economía. Afirma casi unánimemente que "debe" reducirse el gasto público, ya que los objetivos macro-económicos "deben" subordinarse a los de los empresarios e inversores. Menos impuestos generan más beneficios. Pero si aquí termina el debate, ni siquiera se plantean los posibles costes a medio y largo plazo, derivados del recorte de los programas sociales: escasa capacitación laboral, exclusión y marginación. Consideremos otro ejemplo en las noticias. Cada vez que los periodistas informan de una huelga, destacan los perjuicios que acarrea para los consumidores (Goldman y Rajagopal, 1991). Se subrayan los costes a corto plazo y se ignora que los derechos laborales comprenden a toda la sociedad. Si se recortan, esto afectará a quienes consumen sólo gracias a su fuerza de trabajo; es decir, a la mayoría.

Los partidos y los medios lamentan la dificultad de atraer nuevos votantes y audiencias. Se quejan de la apatía de la opinión pública que han "informado". En realidad, le han dado una forma individualizada, impersonal y pasiva. Y se sorprenden de que los jóvenes no se afilien o hagan zapping en los telediarios, "hasta que lleguen los deportes". Si ofreciesen mensajes movilizadores, más allá de los "encuentros electorales con la juventud" y los programas de entretenimiento despolitizado, quizás lograsen recuperarlos. Pero a veces parecen haber generado una "democracia sin ciudadanos" (Entman, 1989).

El resumen de esta pintura tan negra podría ser que las representaciones de la opinión pública eran medios para gobernar, que se han transformado en fines en si mismos. Su prioridad no es favorecer el comienzo del buen gobierno -debate entre iguales- ni su meta -decidir entre todos-. Considerando los principios de la democracia deliberativa, en bastantes ocasiones, construyen un consenso sin debate que en términos más fuertes significa consensos muertos por inanición o imposición. Pero hay que matizar, porque la teoría crítica magnifica los problemas señalados. Las instituciones de la opinión pública seleccionan y jerarquizan de forma bastante eficiente las preferencias de ingentes números de ciudadanos y problemas sociales. A gran escala son imprescindibles. La propuesta sensata no descarta a los gestores de la opinión pública, soñando democracias directas (ciberdemocracia en la Red) o santificando las opiniones de la sociedad civil. Hagamos como si fuesen ciertas las funciones que los gestores de la opinión pública dicen cumplir, exijámoselas y tomemos nuestros derechos en serio dando paso a una democracia deliberativa (Sampedro, 2000b). Las iniciativas descansan, por una parte, en reorganizar los medios, las encuestas y las instituciones políticas para que compitan con pluralidad real y ejerzan un control mutuo. Por otra, se deben cultivar las virtudes ciudadanas.

Debiéramos convencer al público para participar en el juego que determina la legitimidad para representarlo. Hay un buen argumento para ello. Como si se tratase de una liga de fútbol, la competición en la esfera pública resulta imprevisible y está llena de riesgos. Muchos campeonatos se ganan en la última jornada y casi siempre aparece un equipo modesto que se convierte en la revelación de la temporada. La imprevisibilidad procede, en primer lugar, de que las imágenes de la opinión pública circulan a gran escala y no pueden ser controladas (menos aún sus efectos) por quienes las produjeron. Entre otros motivos porque se reciben en contextos muy distintos a los que se originaron.

La sede de un partido, una redacción de un medio o un instituto de sondeo no tienen casi nada que ver con la sala de estar donde la televisión proyecta sus mensajes. Éstos pueden caer en saco roto (indiferencia) o tener el efecto contrario (despertar la risa o el enfado). Por fortuna, tras varias décadas de investigaciones, cualquier campaña de imagen sigue sometida a una incertidumbre muy alta.

Como afirma John B. Thompson (1998), la visibilidad en la esfera pública contemporánea va unida a la vulnerabilidad. Unos segundos de televisión pueden acabar con la carrera de un político. Imágenes "reales" que se cuelan en los medios, por ejemplo, el apaleamiento policial de Rodney King (por supuesto, filmado por un video-aficionado) puede despertar un debate de considerables dimensiones y desmiente el discurso oficial desde sus raíces ${ }^{2}$. Esa imagen puede construirse, tal como hacen los activistas que arrojan billetes ensangrentados en las reuniones del Fondo Monetario Internacional. Y una movilización social que consiga llevar detrás de sí a políticos, periodistas y encuestadores renovará las agendas públicas y políticas (Sampedro, 1997 y 2000a). Hacen faltan muchas ganas, esfuerzo y algo de conocimiento. A ello contribuyen los trabajos de los autores que han colaborado con nosotros en este número especial de nuestra (su) revista.

\section{REFERENCIAS BIBLIOGRÁFICAS}

BENIGER, J. R. (1987): The control revolution: Technological and economic origins of the information society. Cambridge, MA Harvard University Press.

Beniger, J. R. y S. Herbst (1990): "Mass media and the public opinion”. En Hallinan, M. T.; D. M. Kelin y J. Glass (eds.): Change in societal institutions. Nueva York: Plenum Press.

Blumer, H. (1948): "Public opinion and public polling". En American Socilogical Review, 13, 542-554.

CAREY, J. W. (1995): "The press, public opinion and public discourse”. En Glasser, T.L. y C. T. SAlmON (eds.): Public opinion and the communication of consent. Nueva York: The Guildford Press.

2. Las televisiones de EE.UU. emitieron un video doméstico que mostraba la detención y apaleamiento de un conductor negro por cinco policías de Los Angeles. En abril de 1992 la absolución de los agentes provocó tres días de disturbios violentos y asesinatos en L.A. que amenazaron con extenderse a otras ciudades. La Casa Blanca sugirió que la causa de fondo del "problema étnico" eran los programas sociales de los demócratas en los años sesenta y setenta. Las reacciones provocaron un interesante proceso de deliberación colectiva sobre las verdaderas causas (véase Page, 1996: cap. 3). 
EDELMAN, M. (1995): "The influence of rationality claims on public opinion and public policy". En GLASSER, T. y C.T. SALMON (eds.): Public opinion and the communication of consent. Nueva York: The Guildford Press.

Entman, R .M. (1989): Democracy without citizens. Nueva York: Oxford University Press.

Glasser, T. y C. T. SAlmon (eds.) (1995): Public opinion and the communication of consent. Nueva York: Guildford Press.

Glynn, C. J.; Herbst, S.; O’Keefe, G. J. y R. Y. Shapiro (1999): Public opinion. Boulder, CO: Westview Press.

Goldman, R. y A. RajAgOPAL (1991): Mapping begemony. Television news coverage of industrial conflict. Norwood. NJ: Ablex.

Habermas, J. (1986), (v.o. 1962): Historia y crítica de la opinión pública. México: Gustavo Gili.

Habermas, J. (1987), (v.o. 1981): Teoría de la acción comunicativa (vol. 1 y 2). Taurus: Madrid.

HerbSt, S. (1993): Numbered voices. How public opinion bas shaped American politics. Chicago: The University of Chicago Press.

KeY, V. (1967), (v.o. 1961): Public opinion and American democracy. Nueva York: Knopf.

KING, E. y M. SCHUSON (1995): "The press and the illusion of public opinion: The strange case of Ronald Reagan's popularity”. En T. L. Glasser y C. T. SAlmon (eds.) Public opinion and the communication of consent. Nueva York: The Guildford Press.

MARGolis M. y G. A. MaUSER (eds.) (1989): Manipulating public opinion. Essays on public opinion as dependent variable. Pacific Grove, CA: Brooks/Cole.

Noelle-Neumann, E. (1984), (v.o. 1980): The spiral of silence. Our socila skin. Chicago: Chicago University Press.

Page, B. I. (1996): Who deliberates? Mass media in modern democracy. Chicago: Chicago University Press.

SAMPEDRO, V. (1997): Movimientos sociales, debates sin mordaza. Madrid: Centro de Estudios Constitucionales.

SAMPEDRO, V. (2000a): "Media and social movements: An agenda building perspective”. En Fleming, D. (ed.): Formations: 21 st century media studies. Manchester: Manchester University Press.

SAMPEDRO, V. (2000b): Opinión pública y democracia deliberativa. Medios, sondeos y urnas. Madrid: Istmo.

Sampedro, V. y A. Jerez, (2000): Urnas y televisión. Políticos, periodistas y propagandistas. Vídeo y Guía Didáctica de la campaña de las elecciones generales del 2000. Universidad Complutense de Madrid - Ciencias Políticas y Sociales.

Thompson, J. P. (1998): Los medios y la modernidad. Barcelona: Paidós.

Weber, M. (1984), (v.o. 1922): Economia y sociedad. México: Fondo de Cultura Económica.

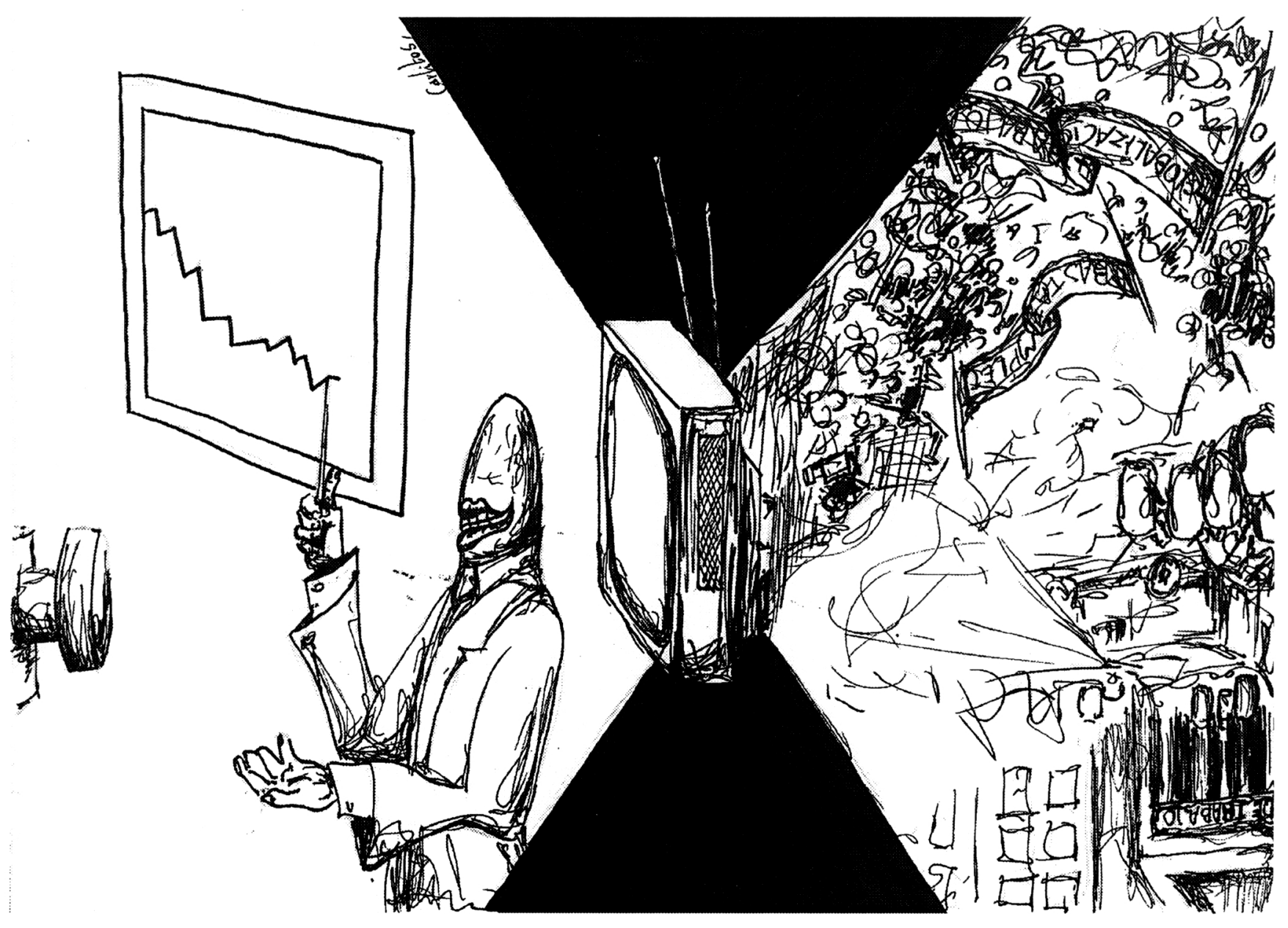

